\title{
O Fundeb no Contexto das Finanças Públicas Municipais de Campo Grande
}

\author{
Maria Dilnéia Espíndola Fernandes' \\ Solange Jarcem Fernandes' \\ 'UniversidadeFederal de Mato Grosso do Sul (UFMS), Campo Grande/MS-Brasil
}

RESUMO - O Fundeb no Contexto das Finanças Públicas Municipais de Campo Grande ${ }^{1}$ O O trabalho analisa a operacionalização do Fundo de Manutenção e Desenvolvimento da Educação Básica e de Valorização dos Profissionais da Educação (Fundeb), entre 2007 a 2009, no contexto das finanças públicas municipais de Campo Grande. Trabalhou-se com a legislação educacional, Balanços Consolidados Municipais, dados do Instituto Nacional de Estudos e Pesquisas Educacionais Anísio Teixeira e a literatura pertinente à temática. Constatou-se que a execução do Fundeb no município ampliou suas receitas de impostos por meio das transferências do fundo estadual para o municipal. O aumento de receitas de impostos não se expressou diretamente no valor do custo/aluno/ano e nos salários docentes no período no município.

Palavras-chave: Política Educacional. Financiamento para Manutenção e Desenvolvimento do Ensino. Fundeb no Município de Campo Grande.

ABSTRACT - The Implementation of Fundeb within the Context of the Municipal Public Finances in Campo Grande. The paper analyzes the operationalization of the Fund for the Development of Basic Education and Appreciation of the Teaching Profession (Fundeb) within the context of the municipal public finances of Campo Grande, from 2007 to 2009. The documents investigated include the educational legislation, the Municipal Consolidated Balance Sheets, data from the Anísio Teixeira National Institute of Educational Studies and Research, and the relevant literature. The execution of the Fundeb in Campo Grande significantly increased the tax revenues due to the state fund transfers. The increase in tax revenue was not directly expressed in the value of cost/pupil/year or in the salaries of the municipal teachers in the period.

Keywords: Educational Policy. Funding for Teaching Maintenance and Development. Fundeb in the Municipality of Campo Grande.

Educação \& Realidade, Porto Alegre, v. 39, n. 3, p. 907-924, jul./set. 2014.

Disponível em: <http://www.ufrgs.br/edu_realidade> 


\section{Introdução}

No contexto da reforma administrativa do Estado brasileiro nos anos 1990, a reforma educacional promovida para a educação básica tomou como imperativo, três grandes eixos da política educacional, a saber: a avaliação, o currículo e o financiamento da educação (Peroni; Oliveira; Fernandes, 2009).

De fato, o diagnóstico de que a crise do capital era crise de Estado, nesse momento histórico, provocou grandes alterações na relação entre Estado e sociedade (Peroni; Adrião, 2005). Tais alterações se processaram com vistas à redução da intervenção do Estado na economia, o que provocou também processos de restrições aos direitos sociais, materializados por meio da política social de forma geral e da política educacional em particular.

Diante disso, no caso da política educacional, observaram-se dois movimentos concomitantes, distintos, mas que concorreram para o mesmo fim. O primeiro foi o movimento de descentralização de ações e encargos da política educacional entre as esferas federativas, tanto no que tange às transferências dessas ações e encargos por parte do governo federal para os governos estaduais e municipais, como também dos estados para seus municípios. O segundo, identificado como processo de municipalização do ensino fundamental, promoveu transferências de matrículas entre as unidades subnacionais, mas, sobretudo, ocasionou, tanto quanto o primeiro movimento, descentralização de ações e encargos entre os estados e seus municípios.

Observou-se que, no caso da política educacional, o principal mecanismo utilizado pelo Estado no que concerne aos dois movimentos acima mencionados, foi o financiamento da educação. O Fundo de Manutenção e Desenvolvimento do Ensino Fundamental e de Valorização do Magistério (Fundef) instituído a partir da Medida Provisória n. 14, de 1996 e a promulgação da Lei n. 9.424 de 1996, (Brasil, 1996a, 1996b) se, por um lado, operou nova organização contábil às contas da educação para manutenção e desenvolvimento do ensino (MDE) e lhes deu maior transparência, por outro, foi o grande indutor dos processos de descentralização e municipalização do ensino fundamental de 1998 a 2007 (Davies, 2006; Pinto, 2007).

Como argumentou Arelaro (2005, p. 1042),

[...] os dados apontam um vertiginoso processo de municipalização de todo o ensino fundamental - de $1^{\text {a }}$ a $8^{\mathrm{a}}$ série - no Brasil, pois, em 2003, já se constatava que dos 31,13 milhões de alunos matriculados no ensino fundamental público (consideradas as redes de ensino estaduais e municipais), cerca de $57,37 \%$ (17,86 milhões de alunos) estavam matriculados no ensino municipal, contra cerca de $42,62 \%$ (13,27 milhões de alunos) nas redes estaduais. 
A substituição do Fundef pelo Fundo de Manutenção e Desenvolvimento da Educação Básica e de Valorização dos Profissionais da Educação (Fundeb), instituído pela Medida Provisória n. 53, de 2006 e regulamentado pela Lei n. 11.494, de 2007 (Brasil, 2006a; 2007a), embora tenha resgatado o conceito de educação básica devido à destinação de receitas para o ensino, não alterou os processos de descentralização e municipalização aprofundados pelo Fundef, assim como não alterou substancialmente os recursos endereçados à MDE, dispostos constitucionalmente pelo Artigo 212 da Constituição Federal de 1988 (Brasil, 1988).

De forma que, embora a vinculação constitucional de recursos garanta mínimos ao ano de arrecadação de impostos para o financiamento de MDE em cada unidade federada, o cenário de composição desta receita em cada uma delas, pode ser extremamente distinto, principalmente quando o ente federativo em tela é o município. Sobre esta questão, recorre-se mais uma vez a Arelaro (2005, p. 1044):

[...] se os municípios tivessem um mesmo padrão de arrecadação de recursos, de tal maneira que se pudesse constatar alguma 'homogeneidade' distributiva, seria fácil discutir e entender o processo radical de 'descentralização' das responsabilidades de atendimento das políticas sociais, porém o quadro brasileiro está longe dessa situação de equilíbrio financeiro entre as diferentes esferas públicas, e entre cada uma delas. Assim, do ponto de vista de arrecadação de tributos, cerca de $70 \%$ dos municípios dependem, exclusivamente do Fundo de Participação dos municípios - o FPM - para as suas despesas regulares, ou seja, para sua 'sobrevivência', e isso traduz que a maioria dos municípios brasileiros não tem autonomia financeira, nem condições de adquiri-la, a menos que adotemos uma reforma tributária radical. Não somos o $2^{\circ}$ pior país, em termos de redistribuição de renda, impunemente!

Embora Arelaro (2005) tenha constatado tal situação em 2005, anterior, portanto, à implantação e operacionalização do Fundeb, as políticas de fundos não alteraram a lógica analisada pela autora. De fato, o que as políticas de fundos promoveram foram arranjos e rearranjos entre os recursos já existentes para MDE, sobretudo sem alterar seu total, que é dado pela vinculação constitucional de recursos - artigo 212 da Constituição Federal (Brasil, 1988).

Não obstante, como os fundos instituíram um valor mínimo de custo/aluno/ano, que é equacionado pelos recursos disponíveis para MDE pela receita de impostos, divididos pelo número de matrículas do censo educacional do ano anterior (no caso do Fundef eram as matrículas do ensino fundamental e agora, no Fundeb, as matrículas da educação básica em cada unidade subnacional), estabeleceu-se uma lógica de migração de recursos entre os estados e seus municípios.

Educação \& Realidade, Porto Alegre, v. 39, n. 3, p. 907-924, jul./set. 2014.

Disponível em: <http://www.ufrgs.br/edu_realidade> 
Ressalta-se que os fundos contábeis normatizaram a função supletiva e complementar na União para aqueles estados cujas receitas de impostos não consigam atingir o valor mínimo do custo/aluno/ano (Brasil, 1996b; 2007a).

Assim, no contexto da reforma administrativa do Estado nos anos 1990, que implicou a reforma da política educacional, interessa, neste trabalho, analisar a operacionalização do Fundeb no âmbito das finanças públicas do município de Campo Grande, à medida que a cidade - capital do estado de Mato Grosso do Sul - é um daqueles municípios que, desde a implantação do Fundef, vem recebendo recursos das políticas de fundos para financiar MDE transferidos pela esfera estadual.

Para tanto, trabalhou-se com a legislação educacional de âmbito federal, estadual e municipal, os Balanços Consolidados do Município de Campo Grande, Sinopses Estatísticas da Educação Básica do Instituto Nacional de Estudos e Pesquisas Educacionais Anísio Teixeira (INEP) e a literatura pertinente à temática.

\section{OFundo deManutençãoe DesenvolvimentodaEducação Básica edeValorização dos Profissionais daEducação (Fundeb) no Município deCampo Grandeno Entretempo de2007a2009}

A Lei n. 11.494 de 2007 (Brasil, 2007a) instituiu novos parâmetros para o financiamento da educação básica brasileira. Tal legislação, aprovada para substituir o Fundef (Brasil, 1996a), elencou novas condições, entre elas a assunção do financiamento da educação básica nas suas etapas e modalidades de ensino, excetuando-se a "[...] educação profissional, que, pela LDB e também com base no Censo do INEP, faria parte da educação básica" (Davies, 2006, p. 763). De forma que o Fundeb,

[...] traz poucos recursos novos para o sistema educacional como um todo, uma vez que apenas redistribui $20 \%$ de grande parte dos recursos que já são constitucionalmente vinculados à educação, entre o governo estadual e as prefeituras com base no número de matrículas na educação básica, o que significa que uns governos ganharão mas outros perderão na mesma proporção, sobretudo quando não houver complementação federal, que será o único recurso novo para o sistema educacional como um todo, que não é tão significativo assim (Davies, 2006, p. 762).

De fato, o Poder Legislativo do município de Campo Grande aprovou a Lei n. 4.448, de 27 de fevereiro de 2007, e, na sequência, a Lei n. 4.560, de 28 de novembro de 2007, instituindo o Conselho de Acompanhamento, Controle Social, Comprovação e Fiscalização dos Recursos do Fundeb (Campo Grande, 2007a; 2007b), em consonância com o artigo 24, da Lei n. 11.494/2007 (Brasil, 2007a). 
Pontua-se que o município de Campo Grande já era um receptor de recursos do Fundef, quando de sua operacionalização frente ao montante de matrículas do ensino fundamental sob seu atendimento (Fernandes; Lourenço, 2009), situação que permaneceu com a lógica do Fundeb.

A propósito, durante a vigência do Fundef (1998 a 2006), o município de Campo Grande ampliou suas matrículas do ensino fundamental em 26\% (Fernandes; Lourenço, 2009). Em 2007, quando começou a vigorar o Fundeb, direcionado à educação básica, continuaram a aumentar as matrículas do ensino fundamental.

De fato, no período de 2007 a 2009, no município em análise, a ampliação das matrículas no ensino fundamental foi da ordem de 1,9\%, enquanto que na educação básica o aumento foi de 4,6\% (Brasil, 2007b; 2008a; 2009a). Como se pode observar, o crescimento das matrículas da educação básica no período do Fundeb foi bem mais tímido que o das matrículas do ensino fundamental do período do Fundef.

Tal movimento se expressou por duas razões: a primeira foi que a oferta do ensino fundamental se universalizou em Campo Grande e manteve a média nacional em proporção ao crescimento vegetativo da população brasileira no período. A segunda foi que a cidade apresenta um déficit histórico relativo ao atendimento à educação infantil (Fernandes; Lourenço, 2009; Fernandes, 2012). Assim pode se observar na tabela 1 que, as matrículas na creche cresceram $45 \%$ no período do Fundeb, ao passo que as matrículas na pré-escola diminuíram de 2007 a $2008,58,8 \%$ e aumentaram $6,6 \%$ de 2008 a 2009. Ao considerar, todavia, de 2007 a 2009, as matrículas na pré-escola diminuíram 37,4\% no período do Fundeb.

Neste sentido,

A sutil oscilação positiva no movimento das matrículas de creche contrasta com a significativa redução das de pré-escola. É necessário acrescentar que essa notável queda, em 2008, se deve à criação do ensino fundamental de nove anos no ano anterior, que incorporou no seu primeiro ano as crianças de seis anos de idade (PMCG, 2008). Para este processo de redução contribuiu o valor por aluno repassado pelo Fundeb às matrículas da pré-escola em período parcial, menor que o das primeiras séries do ensino fundamental nesse ano. $\mathrm{O}$ menor valor por aluno [...] em 2008 contribuiu para tornar menos atrativo o esforço de sua ampliação, ao mesmo tempo em que poderia estar estimulando o ingresso mais rápido e precoce de crianças no ensino fundamental [...]. Em 2009, os valores por aluno da pré-escola e das séries iniciais do ensino fundamental foram equiparados, anulando este movimento [...] (Fundação Carlos Chagas, 2010, p. 338).

Educação \& Realidade, Porto Alegre, v. 39, n. 3, p. 907-924, jul./set. 2014.

Disponível em: <http://www.ufrgs.br/edu_realidade> 
Diante disso, pode-se afirmar que o Fundeb contribuiu pouco para alterar a realidade do atendimento na educação infantil como um todo no município. Com efeito, a população de zero a cinco anos de idade requerente ao direito à educação infantil no município de Campo Grande em 2007, era de 62.578 (Campo Grande, 2011, p. 27). A cobertura de matrículas pela rede municipal de ensino nesse ano foi de 30,72\% para esta população (Brasil, 2007b). Em 2009, a população de zero a cinco anos de idade era de 70.403 (Campo Grande, 2011, p. 27), e a cobertura de matrículas ofertadas na educação infantil pela rede municipal de ensino foi de $26,5 \%$ (Brasil, 2009a).

Tal oscilação para mais e para menos neste atendimento deve-se, sobretudo, pela expansão obrigatória do ensino fundamental instituído pelas Leis federais n. 11.114/2005 e n. 11.274/2006 (Brasil, 2005; 2006b) que vem sendo praticada pelo município a partir de 2008, em interseção com a política educacional do governo federal.

O esforço municipal que se efetiva em um cenário com tamanha oscilação neste atendimento à educação infantil, etapa da educação básica sob sua responsabilidade, demonstra, entre outras situações, o desafio para a administração municipal em operar a recuperação de déficit histórico em relação a este direito educacional. De fato, o crescimento de crianças de zero a cinco anos de idade no município no período de 2007 a 2009 foi de 7.825 em números absolutos e significou, em termos percentuais, crescimento de 12,5\% desta população (Campo Grande, 2011, p. 27).

Significativo foi o aumento de matrículas na educação de jovens e adultos no período, na ordem de $371,8 \%$ no município, como mostra a tabela 1.

Também houve matrículas no ensino médio, o que colocou um problema para o município: de acordo com o artigo 211 da Constituição Federal de 1988 (Brasil, 1988), o ente federativo só poderia ofertar matrículas que não fossem de sua responsabilidade quando tivesse universalizado todas as etapas da educação básica de sua competência. Observou-se que este não seria o caso do município de Campo Grande, frente à demanda ainda não atendida na educação infantil.

A tabela 1 mostra que a rede municipal de ensino absorveu em 2007 quando consideradas as matrículas em todas as dependências administrativas, $43,85 \%$ das mesmas. Ao se considerar as matrículas na rede pública de ensino, a rede municipal foi responsável por $53,4 \%$ delas. Em 2008, a rede municipal de ensino absorveu 45,6 de todas as matrículas e 56\% das matrículas da rede pública de ensino. Em 2009, a rede municipal de ensino operou com $46,4 \%$ do universo de matrículas de todas as redes de ensino e se responsabilizou por $56,7 \%$ das matrículas da rede pública de ensino. Tal movimento no período demonstra que foi crescente a assunção municipal pela oferta do direito à educação por meio de matrículas. Os dados aqui descritos podem ser visualizados na tabela 1 .

912 Educação \& Realidade, Porto Alegre, v. 39, n. 3, p. 907-924, jul./set. 2014. Disponível em: <http://www.ufrgs.br/edu_realidade> 
Fernandes; Fernandes

Tabela 1 - Matrícula na Educação Básica em Todas as Dependências Administrativas no Município de Campo Grande (2007 a 2009)

\begin{tabular}{|c|c|c|c|c|}
\hline $\begin{array}{l}\text { Dependência } \\
\text { administrativa }\end{array}$ & 2007 & 2008 & 2009 & $\begin{array}{c}\text { \% de } \\
\text { crescimento ou } \\
\text { de decréscimo de } \\
\text { matrículas }\end{array}$ \\
\hline \multicolumn{5}{|c|}{ Federal $^{2}$} \\
\hline Creche & 0 & 0 & 0 & 0 \\
\hline Pré-Escola & 0 & 0 & 0 & 0 \\
\hline Ensino Fundamental & 593 & 582 & 628 & $6 \%$ \\
\hline Ensino Médio & 441 & 426 & 496 & $12,5 \%$ \\
\hline Educação de Jovens e Adultos & 0 & 0 & 0 & 0 \\
\hline Total Federal & 1.034 & 1.008 & 1.124 & \\
\hline \multicolumn{5}{|c|}{ Estadual } \\
\hline Creche & 296 & 183 & 226 & $-23,6 \%$ \\
\hline Pré Escola & 140 & 153 & 117 & $-16,4 \%$ \\
\hline Ensino Fundamental & 32.694 & 31.060 & 29.595 & $-9,5 \%$ \\
\hline Ensino Médio & 26.985 & 25.328 & 25.661 & $-4,9 \%$ \\
\hline Educação de Jovens e Adultos & 17.466 & 16.190 & 15.259 & $-12,6 \%$ \\
\hline Total Estadual & 77.581 & 72.914 & 70.858 & \\
\hline \multicolumn{5}{|c|}{ Municipal } \\
\hline Creche & 8.025 & 10.697 & 11.680 & $45,5 \%$ \\
\hline Pré-escola & 11.085 & 6.309 & 7.068 & $-36,2 \%$ \\
\hline Ensino Fundamental & 69.907 & 71.144 & 71.230 & $1,9 \%$ \\
\hline Ensino Médio & 61 & 83 & 82 & $34,4 \%$ \\
\hline Educação de Jovens e Adultos & 901 & 4.644 & 4.251 & $371,8 \%$ \\
\hline Total Municipal & 89.979 & 92.877 & 94.311 & \\
\hline \multicolumn{5}{|c|}{ Privada } \\
\hline Creche & 3.238 & 3.670 & 4.039 & $24,7 \%$ \\
\hline Pré-Escola & 5.742 & 4.756 & 4.437 & $-22,7$ \\
\hline Ensino Fundamental & 17.629 & 18.280 & 18.271 & $3,6 \%$ \\
\hline Ensino Médio & 7.218 & 6.917 & 6.688 & $-7,3 \%$ \\
\hline Educação de Jovens e Adultos & 2.744 & 3.327 & 3.404 & $24 \%$ \\
\hline Total Privada & 35.571 & 36.950 & 36.839 & \\
\hline Total Geral & 205.165 & 203.749 & 203.132 & $-1 \%$ \\
\hline
\end{tabular}

Fonte: Brasil. Instituto Nacional de Estudos e Pesquisas Educacionais Anísio Teixeira. Censo Escolar, 2007b; 2008a; 2009a.

De fato, o número e o movimento das matrículas na educação básica da rede municipal de ensino de Campo Grande, em conjunto com a receita de impostos municipais, operam e determinam a contabilidade do Fundeb em razão do valor mínimo do custo/aluno/ano estabelecido pelo fundo.

Tal situação pode ser reveladora do esforço que o município empreende para garantir o direito à educação básica. No caso de Campo Grande, o esforço se mostrou de forma mais intensa quando da operacionalização do Fundef, pois o município intensificou a magnitude de suas matrículas, como já mencionado aqui.

Ainda assim, há contradições que se apresentam e que promovem restrições ao direito educacional no município. O Fundef incentivou as matrículas no ensino fundamental em âmbito municipal porque cada matrícula significou um valor per capita diante do valor do custo/alu- 
no/ano. Por seu turno, o Fundeb, ao resgatar o conceito de educação básica sem aumentar os recursos para MDE, perdeu a elasticidade de ampliação de matrículas. O que permaneceu em comum na operacionalização dos fundos foi que ambos promoveram aumento de receitas via transferências entre redes de ensino na mesma unidade subnacional, neste caso entre o estado de Mato Grosso do Sul e o município de Campo Grande ${ }^{3}$.

Com efeito, o que no Fundef era $15 \%$ dessas receitas para o ensino fundamental, com o Fundeb é $20 \%$ - embora de forma gradativa, entre 2007 a 2009 - para a educação básica. Essa situação evidencia que as receitas de impostos estaduais e municipais para financiar MDE por meio de um valor de custo/aluno/ano operam no seu esforço máximo.

Essa equação, portanto, pode redimensionar as receitas municipais, como é o caso de Campo Grande. Como o município ampliou as matrículas do ensino fundamental em maior escala durante o Fundef, e em menor perante o Fundeb, o fundo estadual repassa receitas para o município que constam como transferências de receitas dos fundos agora Fundeb - e garantem o aumento de receitas para MDE.

Pode-se observar o aumento das receitas municipais na tabela 2:

Tabela 2 - Receita Total do Município de Campo Grande (2007 a 2009)

\begin{tabular}{|c|c|c|c|}
\hline Ano & $\mathbf{2 0 0 7}$ & $\mathbf{2 0 0 8}$ & $\mathbf{2 0 0 9}$ \\
\hline Receita & $1.464 .417 .745,02$ & $1.693 .985 .806,53$ & $1.771 .924 .619,87$ \\
\hline
\end{tabular}

Fonte: Campo Grande. Balanços Consolidados do Município de Campo Grande, 2007c; 2008; 2009a. Valores indexados pelo INPC/IBGE/dez. 2012.

Observou-se, no período de implantação gradativa do Fundeb, $21 \%$ de incremento da receita total do município de Campo Grande.

\section{Tabela 3 - Base de Incidência de Receitas Próprias e de Transferências do Município de Campo Grande para a Formação e Aplicação em MDE (2007 a 2009)}

\begin{tabular}{|c|c|c|c|}
\hline Ano & $\mathbf{2 0 0 7}$ & $\mathbf{2 0 0 8}$ & $\mathbf{2 0 0 9}$ \\
\hline Total de impostos próprios & $333.119 .336,27$ & $328.464 .959,26$ & $388.075 .068,42$ \\
\hline Total de Transferências da União & $93.200 .741,59$ & $136.060 .567,76$ & $127.888 .574,53$ \\
\hline Total de Transferências do Estado & $296.041 .573,52$ & $342.895 .547,76$ & $339.103 .197,47$ \\
\hline Total Geral & $\mathbf{7 2 2 . 3 6 1 . 6 5 1 , 3 9}$ & $\mathbf{8 0 7 . 4 1 5 . 0 4 5 , 2 6}$ & $\mathbf{8 5 5 . 0 6 6 . 8 4 0 , 4 2}$ \\
\hline 25\% de MDE & $180.590 .412,84$ & $201.853 .761,31$ & $213.766 .710,10$ \\
\hline Aplicado em MDE & $180.168 .759,99$ & $210.783 .163,53$ & $234.431 .231,68$ \\
\hline Percentualquefoi aplicado emMDE & $24,9 \%$ & $26,1 \%$ & $27,4 \%$ \\
\hline
\end{tabular}

Fonte: Campo Grande. Balanços Consolidados do Município de Campo Grande, 2007c; 2008; 2009a. Valores indexados pelo INPC/IBGE/dez. 2012.

A tabela 3 exibe os valores de impostos próprios de Campo Grande e os valores das transferências que recebeu no período, de onde se extraem os $25 \%$ vinculados constitucionalmente para financiar MDE.

Por isso mesmo, desses valores também é extraída a receita do Fundeb nesses anos, de forma gradativa. Embora se apresentem na 
tabela 3 as transferências tanto da união como do estado para o município, pontua-se que Campo Grande não recebe recursos do governo federal para a composição do Fundeb, pois sua receita de impostos tem sido suficiente para atingir o valor mínimo do custo/aluno/ano, como já mencionado aqui.

Pondera-se que, embora a receita total do município tenha crescido $21 \%$ entre 2007 e 2009, as receitas para financiar MDE foram ampliadas em $18,3 \%$ no mesmo período. A razão da diferença entre as duas receitas (total e para MDE) deve-se, em parte, às transferências do Fundeb estadual para o Fundeb municipal e também porque para a composição de MDE, não estão associadas às taxas e contribuições de melhorias, bem como outras receitas, como aquelas, por exemplo, oriundas de Emendas Parlamentares tanto da esfera estadual como da federal.

A tabela 3 mostra a vinculação constitucional de recursos de $25 \%$ da receita de impostos para MDE no município, que são, de fato, os recursos que Campo Grande tem para financiar seu sistema de ensino, incluindo o Fundeb.

Os dados da tabela 3 permitem algumas inferências, tais como: em 2007, em plena vigência do Fundeb e sendo o município receptor de transferências do fundo estadual, ainda assim não aplicou o que deveria em MDE, conforme estabelece o artigo 212 da Constituição Federal de 1988 (Brasil, 1988) e também a Lei Orgânica Municipal, em seu artigo 169 (Campo Grande, 2009b), qual seja, 25\% da receita de impostos em MDE, ao mínimo, por ano; nos anos subsequentes, já com a operacionalização do Fundeb, o município continuou a trabalhar na mesma lógica, pois recebeu recursos do fundo estadual, contudo, contabilizou-os somando-os à sua receita própria para MDE sem subtraí-los, porque não é demais lembrar que a legislação estabelece, no mínimo, 25\% por ano da receita própria de impostos; o aumento de 18,3\% nas receitas para financiar MDE, no período de 2007 a 2009, deve-se em grande parte às transferências dos recursos do fundo estadual, como já foi mencionado, situação que deixa o estado de Mato Grosso do Sul com menos recursos no fundo para financiar o sistema estadual de ensino.

Obviamente que tais transferências de recursos para MDE entre o fundo estadual e os municipais devem-se em razão da detenção das matrículas na educação básica em uma ou outra esfera.

A tabela 4 apresenta os valores da receita do Fundeb em Campo Grande de 2007 a 2009.

Tabela4-Receitas doFundebno Município deCampo Grande (2007 a2009)

\begin{tabular}{|c|c|c|c|}
\hline Ano & $\mathbf{2 0 0 7}$ & $\mathbf{2 0 0 8}$ & $\mathbf{2 0 0 9}$ \\
\hline Contribuiu para o Fundeb & $59.498 .925,22$ & $84.343 .791,30$ & $90.430 .743,80$ \\
\hline $\begin{array}{c}\text { Recebeu na redistribuição } \\
\text { intrarredes }\end{array}$ & $108.878 .723,47$ & $127.667 .342,01$ & $121.966 .492,02$ \\
\hline Total & $168.377 .648,69$ & $212.011 .133,31$ & $206.310 .283,32$ \\
\hline
\end{tabular}

Fonte: Campo Grande. Balanços Consolidados do Município de Campo Grande, 2007c; 2008; 2009a. Valores indexados pelo INPC/IBGE/dez. 2012. 
De fato, os dados da tabela 4 confirmam a análise posta anteriormente, de que o município de Campo Grande é um grande receptor dos recursos do Fundeb. Em 2007, 64,6\% do Fundeb municipal foram transferências do fundo estadual; em 2008, foram $60,2 \%$ e em 2009, 59,1\%. Importa considerar que as transferências entre fundos nestes anos se deram de forma gradativa, portanto o Fundeb, ainda nesse período, não estava operando em sua totalidade.

Ainda, os valores expressos na tabela 4 mostram que o Fundeb em Campo Grande - ressalta-se, operacionalizado de forma gradativa nestes anos - cresceu em sua totalidade de valores na ordem de 22,5\%.

Há que se considerar aqui tal situação, sobretudo, porque se trata de um fundo que vincula também, no mínimo, $60 \%$ das suas receitas para pagamento de salários dos profissionais da educação básica, como é o caso do Fundeb. Isso significou que contas de MDE não foram pagas no exercício do ano corrente e também que os salários dos profissionais da educação básica não receberam o mínimo de $60 \%$ das receitas do Fundeb no município. Esta é uma das razões pelas quais os profissionais da educação básica percebem, via de regra, gratificações salariais no município de Campo Grande.

A propósito, o cenário das gratificações salariais no município tem sido recorrente: nunca foi parte das políticas de fundos, exclusivamente. A novidade foi que, tanto com o Fundef quanto com o Fundeb, as gratificações se tornaram instrumentos de legitimação por parte do Poder Executivo em negociações salariais com a categoria do Magistério por meio de sua direção sindical.

Assim, ainda durante a vigência do Fundef, legitimou-se a Gratificação pelo Efetivo Exercício do Ensino Fundamental (Gratef), com percentual de 32,38\%, incidindo sobre os salários, por meio da Lei n. 3.442/1998 (Campo Grande, 2004), e nesta mesma Lei, no artigo 3º, em observância ao princípio da isonomia, foi concedido para os demais servidores do grupo magistério, em efetivo exercício na sede da Secretaria Municipal de Educação e nas unidades de educação infantil e de ensino médio da rede municipal de ensino, os mesmos percentuais de reajustes salariais nas mesmas datas previstas para o Gratef. Tal gratificação foi identificada como Gratificação do Tesouro (Grates), pois era paga com recursos próprios da Fonte 01, fonte orçamentária municipal (Campo Grande, 1998). Em 2004, mediante a Lei n. 4.146/2004 (Campo Grande, 2004), 2,38\% do percentual de 32,38\%, tanto da Gratef quanto da Grates, foram incorporadas ao vencimento base dos profissionais da educação. O artigo $8^{\circ}$, da Lei n. 4.146/2004 (Campo Grande, 2004), dispôs que, a incorporação dos restantes $30 \%$ das gratificações ao salário do magistério, seria pago até 2008. De fato, somente em 2008 as gratificações foram totalmente incorporadas aos salários.

Pontua-se que o cenário das gratificações salariais para o magistério permitiu, no período, que os recursos dos fundos vinculados aos salários, ainda que em termos mínimos, não fossem gastos em sua totalidade para essa finalidade.

916 Educação \& Realidade, Porto Alegre, v. 39, n. 3, p. 907-924, jul./set. 2014 Disponível em: <http://www.ufrgs.br/edu_realidade> 
Fernandes; Fernandes

As tabelas 5, 6 e 7 expressam o valor praticado por aluno/ano pelo município de Campo Grande (Campo Grande, 2007c; 2008; 2009a).

A opção metodológica aqui trabalhada para o cálculo do valor per capita operacionalizado pela rede municipal de ensino considerou a receita realizada demonstrada nos Balanços Consolidados do Município e nos Demonstrativos Financeiros do Conselho de Acompanhamento do Fundeb em conjunto com as matrículas consideradas para cada ano e o fator de ponderação utilizado para o cálculo das etapas e modalidade de ensino. Na receita realizada pelo município estão computados o saldo do exercício anterior e os rendimentos financeiros do período. Tal procedimento metodológico foi necessário, pois o valor anual por aluno estimado apresentado pelas Portarias Interministeriais disponibilizados pelo Fundo Nacional de Desenvolvimento da Educação (FNDE) para o conjunto dos municípios e da rede estadual de ensino do estado de Mato Grosso do Sul, foram realizados com base nas receitas estimadas (Brasil, 2007d; 2008b, 2009b), por isso há diferença significativa entre a receita estimada e a receita efetivamente realizada pelas redes. Diante disso, as tabelas 5, 6 e 7 mostram a receita efetivamente realizada pelo município de Campo Grande para o valor per capita/aluno do Fundeb durante os anos de 2007, 2008 e 2009.

Tabela 5 - Educação Básica - matrículas consideradas, fator de ponderação e valor per capita/aluno do Fundeb com receita realizada no município de Campo Grande (2007)

\begin{tabular}{|c|c|c|c|}
\hline Educação básica & $\begin{array}{c}\text { Matrícula } \\
\text { Considerada }\end{array}$ & $\begin{array}{c}\text { Fator de } \\
\text { Ponderação }\end{array}$ & $\begin{array}{c}\text { Valor per capita com } \\
\text { receita realizada }\end{array}$ \\
\hline Creche & 1.513 & 0,8 & $1.908,91$ \\
\hline Fundamental Inicial Urbano & 38.382 & 1 & $2.386,14$ \\
\hline Pré-Escola & $3.011,3$ & 0,9 & $2.147,52$ \\
\hline Fundamental Inicial Rural & 865 & 1,05 & $2.505,44$ \\
\hline Fundamental Final & 30.360 & 1,1 & $2.624,75$ \\
\hline Fundamental Final Rural & 549 & 1,15 & $2.744,06$ \\
\hline Ensino Integral & 242 & 1,25 & $2.982,68$ \\
\hline Educação Especial & 829 & 1,2 & $2.863,37$ \\
\hline Educação de Jovens e Adultos & 291,7 & 0,7 & $1.670,30$ \\
\hline
\end{tabular}

Fonte: Brasil. Instituto Nacional de Estudos e Pesquisas Educacionais Anísio Teixeira. Censo escolar, 2006c. Campo Grande. Balanço Consolidado do Município de Campo Grande, 2007c. Demonstrativo Financeiro dos Recursos Transferidos pelo Fundeb, 2007d. Números fracionados-equivalem a 1/3 de matrículas de alunos conforme a legislação. Valores indexados pelo INPC/IBGE/dez. 2012.

Tabela 6 - Educação Básica - matrículas consideradas, fator de ponderação e valor per capita/aluno do Fundeb com receita realizada no município de Campo Grande (2008)

\begin{tabular}{|c|c|c|c|}
\hline Educação básica & $\begin{array}{c}\text { Matrícula } \\
\text { Considerada }\end{array}$ & $\begin{array}{c}\text { Fator de } \\
\text { Ponderação }\end{array}$ & $\begin{array}{c}\text { Valor per capita com } \\
\text { receita realizada }\end{array}$ \\
\hline Creche & 5.360 & 1,10 & $2.949,80$ \\
\hline Pré-Escola Integral & 3.858 & 1,15 & $3.083,88$ \\
\hline Pré-Escola Parcial & $3.499,3$ & 0,9 & $2.413,47$ \\
\hline Fundamental Inicial Urbano & 38.347 & 1 & $2.681,64$ \\
\hline Fundamental Inicial Rural & 836 & 1,05 & $2.815,72$ \\
\hline
\end{tabular}

Educação \& Realidade, Porto Alegre, v. 39, n. 3, p. 907-924, jul./set. 2014.

Disponível em: <http://www.ufrgs.br/edu_realidade> 


\begin{tabular}{|c|c|c|c|}
\hline Fundamental Final Urbano & 29.323 & 1,1 & $2.949,80$ \\
\hline Fundamental Final Rural & 591 & 1,15 & $3.083,88$ \\
\hline Escola Integral & 246 & 1,25 & $3.352,06$ \\
\hline Educação Especial & 834,7 & 1,2 & $3.217,96$ \\
\hline Educação de Jovens e Adultos & 536 & 0,7 & $1.877,14$ \\
\hline Indígena/Quilombolas & 32,7 & 1,2 & $3.217,96$ \\
\hline Conveniada Creche Integral & 954 & 0,95 & $2.547,55$ \\
\hline Conveniada Creche & 100,7 & 0,8 & $2.145,31$ \\
\hline Conveniada Pré-Escola integral & 306,7 & 1,15 & $3.083,88$ \\
\hline Conveniada Pré-Escola & 30 & 0,9 & $2.413,47$ \\
\hline Conveniada Educação Especial & 333,2 & 1,2 & $3.217,96$ \\
\hline
\end{tabular}

Fonte: Brasil. Instituto Nacional de Estudos e Pesquisas Educacionais Anísio Teixeira. Censo Escolar, 2007. Campo Grande. Balanco Consolidado do Município de Campo Grande, 2008a. Demonstrativo

Financeiro dos Recursos Transferidos pelo Fundeb, 2008b. Números Fracionados - equivalem a 2/3 de matrículas de alunos conforme a legislação. Valores indexados pelo INPC/IBGE/dez. 2012.

A tabela 6 acima, assim como a 7 abaixo, apresentam a designação dada pelo artigo 13, do Decreto n. 6.253, de 13 de novembro de 2007 (Brasil, 2007c) que normatiza, no âmbito da distribuição dos recursos do Fundeb, aquelas matrículas que se encontram na esfera das instituições conveniadas, a saber:

Admitir-se-á, a partir de $1^{\circ}$ de janeiro de 2008, para efeito da distribuição dos recursos do FUNDEB, o cômputo das matrículas efetivadas na educação infantil oferecida na pré-escola para crianças de quatro e cinco anos por instituições comunitárias, confessionais ou filantrópicas sem fins lucrativos, conveniadas com o poder executivo competente (Brasil, 2007c).

Tabela 7 - Educação Básica - matrículas consideradas, fator de ponderação e valor per capita/aluno do Fundeb com receita realizada no município de Campo Grande (2009)

\begin{tabular}{|c|c|c|c|}
\hline Educação básica & Matrícula & $\begin{array}{c}\text { Fator de } \\
\text { Ponderação }\end{array}$ & $\begin{array}{c}\text { Valor per capita com } \\
\text { receita realizada }\end{array}$ \\
\hline Creche & 10.674 & 1,10 & $2.606,61$ \\
\hline Pré-Escola Integral & 3.435 & 1,2 & $2.843,57$ \\
\hline Pré-Escola Parcial & 2.851 & 1 & $2.369,64$ \\
\hline Fundamental Inicial Urbano & 41.253 & 1 & $2.369,64$ \\
\hline Fundamental Inicial Rural & 1.018 & 1,05 & $2.488,12$ \\
\hline Fundamental Final Urbano & 27.520 & 1,1 & $2.606,54$ \\
\hline Fundamental Final Rural & 760 & 1,15 & $2.725,09$ \\
\hline Ensino Fundamental Integral & 638 & 1,25 & $2.962,06$ \\
\hline Educação Especial & 1.022 & 1,2 & $2.843,57$ \\
\hline Educação de Jovens e Adultos & 4.585 & 0,8 & $1.895,71$ \\
\hline Indígena/Quilombolas & 46 & 1,2 & $2.843,57$ \\
\hline Conveniada Creche integral & 1.701 & 0,95 & $2.251,16$ \\
\hline Conveniada Creche parcial & 52 & 0,8 & $1.895,71$ \\
\hline Conveniada Pré-Escola integral & 460 & 1,2 & $2.843,57$ \\
\hline Conveniada Pré-Escola parcial & 45 & 1 & $2.369,64$ \\
\hline Conveniada Educação Especial & 326 & 1,2 & $2.843,57$ \\
\hline
\end{tabular}

Fonte: Brasil. Instituto Nacional deEstudose Pesquisas Educacionais Anísio Teixeira. Censo escolar, 2008 Campo Grande. Balanço Consolidado do Município de Campo Grande, 2009a. Demonstrativo Financeiro dos Recursos Transferidos pelo FUNDEB, 2009c. Valores indexados pelo INPC/IBGE/dez. 2012. 
Devido à natureza deste trabalho, considera-se, para efeito de análise, o exemplo do valor aluno/ano com a receita realizada porque é este efetivamente o valor que foi gasto, de acordo com os dados de balanços consolidados pelo município de Campo Grande, para o ensino fundamental inicial urbano, que tem como fator de ponderação 1 . Assim, o valor em 2007 foi de R $2.386,14$, em 2008, de R 2.681,64 e em 2009, de 2.369,64.

Diante disso, o valor aluno/ano para o ensino fundamental inicial urbano aumentou na ordem de 12,3\% entre 2007 e 2008; contudo, reduziu 11,6\% entre 2008 e 2009 no município.

Apesar da redução do valor aluno/ano no município de Campo Grande, suas receitas, tanto as totais como as para financiar MDE que compõem o Fundeb, aumentaram no período considerado, conforme mostraram as tabelas 2, 3 e 4. Somente diminuíram as receitas do Fundeb em 2009, como mostra também a tabela 4.

Assim, a diminuição do valor do custo/aluno/ano deve-se, por um lado, ao fato de que a decisão de fixar nacionalmente o valor ficou sob a responsabilidade da Comissão Intergovernamental de Financiamento para a Educação Básica de Qualidade (Brasil, 2007a), situação que impacta o valor do custo/aluno/ano nas unidades subnacionais. Pontua-se que as decisões da Comissão antes mencionada para estabelecer o valor mínimo do custo/aluno/ano, nem sempre considera o processo inflacionário, entre outras perdas da economia (Confederação Nacional dos Trabalhadores em Educação, 2008). Por outro lado, a redução do valor do custo/aluno/ano em âmbito municipal pode significar tanto redução como ampliação de matrículas na educação básica, em razão dos fatores de ponderação adotados, que implicam valores diferenciados para etapas e modalidades da educação básica, como demonstrado nas tabelas 5, 6 e 7. De fato, de acordo com os dados da tabela 1, Campo Grande oscilou para mais e para menos a oferta de matrículas na pré-escola entre 2007 e 2009.

Assim, a implantação das políticas de fundos por parte da União redimensionou no âmbito municipal as finanças públicas para MDE. No caso do município de Campo Grande, a implantação dos fundos contribuiu de forma importante para a recomposição de sua receita. Também em decorrência disto, o município ampliou seu atendimento para a educação básica.

Pelo que foi exposto até então, deve-se considerar o salário do magistério no município em tela, em decorrência da garantia legal de, no mínimo, 60\% das receitas dos fundos (Brasil, 1996a; 2007b). A tabela 8 mostra os valores salariais de início e de final de carreira dos professores. 
O Fundeb no Contexto das Finanças Públicas Municipais de Campo Grande

Tabela 8-Salário Inicial e Final dos Profissionais do Magistério do Município de Campo Grande 20 Horas Semanais (2006, 2007, 2008 e 2009)

\begin{tabular}{|c|c|c|c|c|c|}
\hline Habilitação & Vencimento & $\mathbf{2 0 0 6}$ & $\mathbf{2 0 0 7}$ & $\mathbf{2 0 0 8}$ & $\mathbf{2 0 0 9}$ \\
\hline \multirow{2}{*}{$\begin{array}{c}\text { Ensino Médio } \\
\text { Magistério }\end{array}$} & Inicial & 579,52 & 622,15 & 655,07 & 691,77 \\
\cline { 2 - 6 } & Final & $1.067,73$ & $1.146,28$ & $1.206,92$ & $1.274,52$ \\
\hline \multirow{2}{*}{$\begin{array}{c}\text { Licenciatura } \\
\text { Plena (Graduação) }\end{array}$} & Inicial & 840,31 & 933,23 & 982,61 & $1.037,66$ \\
\cline { 2 - 6 } & Final & $1.548,21$ & $1.719,42$ & $1.810,38$ & $1.911,78$ \\
\hline \multirow{2}{*}{ Pós Graduação } & Inicial & 924,35 & $1.026,55$ & $1.080,87$ & $1.141,41$ \\
\cline { 2 - 6 } & Final & $1.703,04$ & $1.891,36$ & $1.991,42$ & $2.102,96$ \\
\hline \multirow{2}{*}{ Mestrado } & Inicial & $1.008,36$ & $1.119,88$ & $1.179,13$ & $1.245,17$ \\
\cline { 2 - 6 } & Final & $1.857,83$ & $2.063,29$ & $2.172,45$ & $2.294,12$ \\
\hline \multirow{2}{*}{ Doutorado } & Inicial & $1.092,37$ & $1.213,16$ & $1.277,34$ & $1.348,88$ \\
\cline { 2 - 6 } & Final & $1.972,61$ & $2.235,16$ & $2.353,41$ & $2.485,22$ \\
\hline
\end{tabular}

Fonte: Sindicato Campo-Grandense dos Profissionais da Educação Pública (ACP), 2011. Valores indexados pelo INPC/IBGE/dez. 2012.

Optou-se por verificar os dados salariais desde 2006 para fins de comparação. O reajuste salarial praticado no vencimento básico inicial e final para os profissionais da educação básica nos três primeiros anos do Fundeb foi de $11,1 \%$, enquanto que a receita deste fundo cresceu $22,5 \%$, e o aumento da receita para MDE foi de $18,3 \%$ no município nos anos de 2007 a 2009, conforme demonstrado na tabela 3.

Pontua-se que a rede municipal de ensino de Campo Grande trabalhou com 4.160 professores na educação básica em 2007; 4.337 em 2008 e 4.448 em 2009 (Campo Grande, 2012). O aumento de 288 cargos/ funções nesses anos significou um acréscimo de 7\% em termos de contratação da força de trabalho. Não obstante, em 2007, 48,26\% da força de trabalho docente municipal, estava contratada temporariamente, em 2008, os contratos temporários de trabalhos representaram 25,20\% do total desta força e, em 2009, tais contratos representaram ainda 28,5\% da força de trabalho (Campo Grande, 2012).

\section{Considerações Finais}

Objetivou-se, com este trabalho, analisar em que medida a reforma administrativa do Estado brasileiro, encetada a partir dos anos 1990, implicou também a reforma da política educacional. Observou-se que, para o setor educacional, a reforma administrativa do Estado operou nos eixos do financiamento, avaliação e currículo. Neste trabalho optou-se pela análise da operacionalização do Fundeb no contexto das finanças públicas municipais de Campo Grande.

De fato, a reforma da política educacional induzida pela União colocou para as unidades subnacionais novas tarefas, cuja principal característica foi delegar funções e encargos para os entes federativos, imperativo que culminou em processos de descentralização e municipalização de etapas da educação básica. Nessa conjuntura, ganharam destaques as políticas de fundos, materializadas pelo Fundef e Fundeb.

920 Educação \& Realidade, Porto Alegre, v. 39, n. 3, p. 907-924, jul./set. 2014 Disponível em: <http://www.ufrgs.br/edu_realidade> 
Observou-se que, no caso do município de Campo Grande, a implantação do Fundeb ocorreu quando a rede municipal de ensino já se encontrava com o ensino fundamental municipalizado e com cobertura universalizada. A educação infantil, no entanto, permanece ainda com restrições na sua oferta, ao passo que o município vem atendendo ao ensino médio, etapa da educação básica que não é de sua competência e responsabilidade.

Constatou-se que o Fundeb provocou redimensionamentos nas finanças públicas municipais de Campo Grande, em razão de que, pelo índice de municipalização de matrículas operado, o município vem sendo, paulatinamente, receptor de transferências de recursos do fundo estadual. Não obstante, observou-se oscilação para mais e para menos no valor do custo/aluno/ano nos três primeiros anos de execução do Fundeb. Também se verificou que a execução do Fundeb provocou reajustes salariais para os profissionais do magistério, contudo, permanece o desafio para a administração municipal e para a força de trabalho docente do município a recuperação de perdas históricas em termos salariais e de carreira.

Recebido em 07 de maio de 2013 Aprovado em 30 de setembro de 2013

\section{Notas}

10 trabalho integra a pesquisa: Remuneração de Professores de Escolas Públicas de Educação Básica no contexto do Fundeb e do PSPN. Financiamento: Coordenação de Aperfeiçoamento de Pessoal de Nível Superior (CAPES), Programa Observatório da Educação.

2 As matrículas da dependência federal são as do Colégio Militar de Campo Grande.

3 Os impostos que compõem o Fundeb são: Fundo de Participação dos Estados (FPE), Fundo de Participação dos Municípios (FPM), Impostos Sobre Operações Relativas à Circulação de Mercadorias e Serviços de Transporte Interestadual e de Comunicações (ICMS), Lei Complementar n. 87/1996, (Lei Kandir), Imposto Sobre Produtos Industrializados (IPI-Exportação), Imposto Sobre Transmissão Causa Mortis e Doação de Bens e Direitos (ITCD), Imposto Sobre a Propriedade de Veículos Automotores (IPVA) e Imposto Territorial Rural (ITR).

\section{Referências}

ARELARO, Lisete Regina Gomes. O Ensino Fundamental no Brasil: avanços, perplexidades e tendências. Educação e Sociedade, Campinas, v. 26, n. 92, [Especial], p. 1039-1066, out. 2005.

BRASIL. Constituição da República Federativa do Brasil. Diário Oficial da União, Brasília, DF, 5 out. 1988.

BRASIL. Emenda Constitucional n. 14, de 12 de setembro de 1996. Modifica os art. 34, 208, 211 e 212 da Constituição Federal e dá nova redação ao art. 60 do Ato das Disposições Constitucionais Transitórias. Diário Oficial da União, Brasília, DF, 13 set. 1996a.

Educação \& Realidade, Porto Alegre, v. 39, n. 3, p. 907-924, jul./set. 2014.

Disponível em: <http://www.ufrgs.br/edu_realidade> 
BRASIL. Lei n. 9.424, de 24 de dezembro de 1996. Dispõe sobre o Fundo de Manutenção e Desenvolvimento do Ensino Fundamental e de Valorização do Magistério - FUNDEF. Diário Oficial da União, Brasília, DF, 26 dez. 1996b.

BRASIL. Lei n. 11.114, de 16 de maio de 2005. Altera os arts. $6^{\circ}, 30$ e 87 da Lei n. 9.394, de 20 de dezembro de 1996, com o objetivo de tornar obrigatório o início do ensino fundamental aos seis anos de idade. 2005. Diário Oficial da União, Brasília, DF. Disponível em: <http://www.planalto.gov.br/ccivil_o3/Ato_20042006/2005/Leil1114.htm>. Acesso em: 22 abr. 2012.

BRASIL. Emenda Constitucional n. 53, de 19 de dezembro de 2006. Dá nova redação aos art. 7º 23, 30, 206, 208, 211 e 212 da Constituição Federal e ao art. 60 do Ato das Disposições Constitucionais Transitórias. Diário Oficial da União, Brasília, DF, 20 dez. 2006a.

BRASIL. Lei n. 11.274, de 6 de fevereiro de 2006. Altera a redação dos arts. 29, 30, 32 e 87 da Lei n. 9.394, de 10 de dezembro de 1996, que estabelece as diretrizes e bases da educação nacional, dispondo sobre a duração de 9 (nove) anos para o ensino fundamental, com matrícula obrigatória a partir dos 6 (seis) anos de idade. Diário Oficial da União, Brasília, DF, 2006b. Disponível em: <http:www.planalto. gov.br/ccvil_03/_Ato2004-2006/2006/Lei11274.htm>. Acesso em: 22 abr. 2012.

BRASIL. Lei n. 11.494, de 20 de junho de 2007. Regulamenta o Fundo de Manutenção e Desenvolvimento da Educação Básica e de Valorização dos Profissionais da Educação - FUNDEB, de que trata o art. 60 do Ato das Disposições Constitucionais Transitórias; altera a Lei no 10.195, de 14 de fevereiro de 2001; revoga dispositivos das Leis nos 9.424, de 24 de dezembro de 1996, 10.880, de 9 de junho de 2004, e 10.845, de 5 de março de 2004; e dá outras providências. Diário Oficial da União, Brasília, DF, 2007a. Disponível em: <http://www.planalto.gov.br/ccivil_03/_ato2007-2010/2007/Lei/L11494.htm>. Acesso em: 21 mar. 2012.

BRASIL. Instituto Educacional de Estudos e Pesquisas Educacionais Anísio Teixeira. Censo Escolar. 2006c. Disponível em: <http://portal.inep.gov.br/basica-censo-escolar-matricula>. Acesso em: 27 mar. 2012.

BRASIL. Instituto Educacional de Estudos e Pesquisas Educacionais Anísio Teixeira. Censo Escolar. 2007b. Disponível em: <http://portal.inep.gov.br/basica-censo-escolar-matricula>. Acesso em: 27 mar. 2012.

BRASIL. Presidência da República. Casa Civil. Subchefia para Assuntos Jurídicos. Decreto n. 6.253, de 13 de novembro de 2007. Dispõe sobre o Fundo de Manutenção e Desenvolvimento da Educação Básica e de Valorização dos Profissionais da Educação - Fundeb, regulamenta a Lei n.o 11.494, de 20 de junho de 2007, e dá outras providências. Diário Oficial da União, Brasília, DF, 2007c. Disponível em: <http://www.planalto.gov.br/ccivil_03/_ato2007-2010/2007/Decreto/D6253.htm>. Acesso em: 29 abr. 2013.

BRASIL. Fundo Nacional de Desenvolvimento da Educação. Valor Anual por aluno estimado no âmbito do Distrito Federal e dos Estados, e estimativa de receita do Fundo de Manutenção e Desenvolvimento da Educação Básica e de Valorização dos Profissionais da Educação. 2007d. Disponível em: <http://www. fnde.gov.br/financiamento/fundeb/consult>. Acesso em: 10 maio 2011.

BRASIL. Instituto Educacional de Estudos e Pesquisas Educacionais Anísio Teixeira. Censo Escolar. 2008a. Disponível em: <http://portal.inep.gov.br/basica-censo-escolar-matricula>. Acesso em: 27 mar. 2012.

BRASIL. Fundo Nacional de Desenvolvimento da Educação. Valor Anual por aluno estimado no âmbito do Distrito Federal e dos Estados, e estimativa de receita do Fundo de Manutenção e Desenvolvimento da Educação Básica e de 
Valorização dos Profissionais da Educação. Anexo I Portaria Interministerial n. 1.027, de 19 de agosto de 2008. 2008b. Disponível em:<http://www.fnde.gov.br/ financiamento/fundeb/consult $>$. Acesso em: 10 maio 2011.

BRASIL. Instituto Educacional de Estudos e Pesquisas Educacionais Anísio Teixeira. Censo Escolar. 2009a. Disponível em: <http://portal.inep.gov.br/basica-censo-escolar-matricula>. Acesso em: 27 mar. 2012.

BRASIL. Fundo Nacional de Desenvolvimento da Educação. Valor Anual por aluno estimado no âmbito do Distrito Federal e dos Estados, e estimativa de receita do Fundo de Manutenção e Desenvolvimento da Educação Básica e de Valorização dos Profissionais da Educação. Anexo I Portaria Interministerial n. 221, de 10 de março de 2009. 2009b. Disponível em: <http://www.fnde.gov.br/ financiamento/fundeb/consult $>$. Acesso em: 10 maio 2011.

CAMPO GRANDE. Lei n. 3.442, de 24 de março de 1998. Dispõe sobre o reajuste salarial aos servidores da administração municipal de Campo Grande e dá outras providências. Campo Grande: 1998. Disponível em: <http://www.camara. ms.gov.br>. Acesso em: 10 out. 2010.

CAMPO GRANDE. Lei n. 4.146, de $1^{\circ}$ de abril de 2004. Aprova as tabelas de vencimento dos servidores do Poder Executivo municipal e dá outras providências. Campo Grande: 2004. Disponível em: <http://www.camara.ms.gov.br>. Acesso em: 10 out. 2010 .

CAMPO GRANDE. Lei n. 4.448, de 27 de fevereiro de 2007. Dispõe sobre a criação do Conselho Municipal do Fundeb. 2007a. Disponível em: <http://www.camara.ms.gov.br/?secao=legislacoes $>$. Acesso em: 26 fev. 2012.

CAMPO GRANDE. Lei n. 4.560, de 28 de novembro de 2007. Dispõe sobre alteração do Conselho Municipal do Fundeb. 2007b. Disponível em: <http://www. camara.ms.gov.br/?secao=legislacoes $>$. Acesso em: 26 fev. 2012.

CAMPO GRANDE. Secretaria Municipal de Receita. Balanços Consolidados do Município de Campo Grande. Campo Grande, 2007c.

CAMPO GRANDE. Secretaria Municipal de Receita. Demonstrativo Financeiro dos Recursos Transferidos pelo Fundeb. Campo Grande, 2007d.

CAMPO GRANDE. Secretaria Municipal de Receita. Balanços Consolidados do Município de Campo Grande. Campo Grande, 2008a.

CAMPO GRANDE. Secretaria Municipal de Receita. Demonstrativo Financeiro dos Recursos Transferidos pelo Fundeb. Campo Grande, 2008b.

CAMPO GRANDE. Secretaria Municipal de Receita. Balanços Consolidados do Município de Campo Grande. Campo Grande, 2009a.

CAMPO GRANDE. Câmara Municipal de Campo Grande. Lei Orgânica do Município de Campo Grande - MS. 2009b.

CAMPO GRANDE. Secretaria Municipal de Receita. Demonstrativo Financeiro dos Recursos Transferidos pelo Fundeb. Campo Grande, 2009c.

CAMPO GRANDE. Secretaria Municipal de Educação. Indicadores Educacionais da REME. Campo Grande: SEMED, 2011.

CAMPO GRANDE. Secretaria Municipal de Educação. Professores da REME. Campo Grande: SEMED, 2012.

CONFEDERAÇÃO NACIONAL DOS TRABALHADORES EM EDUCAÇÃO. Congresso Nacional da CNTE, 30., Cadernos de Resoluções. Brasília, 2008. Disponível em: <http://www.cnte.org.br/images/stories/caderno_de_resolucoes_2008. pdf>. Acesso em: 1 maio 2013.

Educação \& Realidade, Porto Alegre, v. 39, n. 3, p. 907-924, jul./set. 2014

Disponível em: <http://www.ufrgs.br/edu_realidade> 
DAVIES, Nicholas. Fundeb: a redenção da educação básica? 2006. Disponível em: <http://www.scielo.br/pdf/es/v27n96/a07v2796.pdf>. Acesso em: 21 mar. 2012.

FERNANDES, Maria Dilnéia Espíndola; LOURENÇO, Francielle de Souza. O Impacto da Implantação do Fundef na Educação Infantil no Município de Campo Grande/MS (1997 a 2000). Jornal de Políticas Educacionais, Curitiba, UFPR, n. 5, p. 59-70, jan./jun. 2009.

FERNANDES, Maria Dilnéia Espíndola. Gestão da Educação Infantil: entre a herança assistencial e o atendimento tardio. In: CONGRESSO IBERO AMERICANO DE POLÍTICA E ADMINISTRAÇÃO DA EDUCAÇÃO, 3., 2012, Zaragoza/ ES. Anais... Disponível em: <http://www.anpae.org.br/website/images/stories/ capa_ib.png >. Acesso em: 2 mar. 2013.

FUNDAÇÃO CARLOS CHAGAS. Educação Infantil no Brasil: avaliação qualitativa e quantitativa. Relatório Final. Coordenação Maria Malta Campos. nov. 2010. $424 \mathrm{p}$.

SINDICATO CAMPO-GRANDENSE DOS PROFISSIONAIS DA EDUCAÇÃO PÚBLICA (ACP). Tabelas Salariais. 2011. Disponível em: <http://www.acpms.com. $\mathrm{br} /$ ?a=salario $>$. Acesso em: 28 mar. 2012.

PERONI, Vera Maria Vidal; ADRIÃO, Theresa. Público Não-estatal: estratégias para o setor educacional brasileiro. In: ADRIÃO, Theresa; PERONI, Vera Maria Vidal. O Público e o Privado na Educação: interfaces entre Estado e sociedade. São Paulo: Xamã, 2005. P. 137-153.

PERONI, Vera Maria Vidal; OLIVEIRA, Regina Tereza Cestari de; FERNANDES, Maria Dilnéia Espíndola. Estado e Terceiro Setor: as novas regulações entre o público e o privado na gestão da educação básica brasileira. Educação e Sociedade, Campinas, v. 30, n. 108, p. 761-778, out. 2009.

PINTO, José Marcelino de Rezende. A Política Recente de Fundos para o Financiamento da Educação e seus Efeitos no Pacto Federativo. Educação e Sociedade, Campinas, v. 28, n. 100 [Especial], p. 877-897, out. 2007.

Maria Dilnéia Espíndola Fernandes é professora associada da Universidade Federal de Mato Grosso do Sul do Programa de Pós-Graduação em Educação - Cursos de Mestrado e Doutorado e do Departamento de Educação. E-mail:mdilneia@uol.com.br

Solange Jarcem Fernandes é professora do Departamento de Educação da Universidade Federal de Mato Grosso do Sul..

E-mail: solangejarcem@yahoo.com.br 